\title{
Model Persamaan Struktural Mengekspolarasi Jalur Path Kepemimpinan Transformasional dan Motivasi Terhadap Kinerja Pegawai TAF
}

\author{
Dimas Wibisono \\ Universitas Alma Ata, Yogyakarta, Indonesia \\ Email : dimaswibisono@almaata.ac.id
}

(Diterima: September 2021; Direvisi: Oktober 2021; Dipublikasikan: Januari 2022)

\begin{abstract}
ABSTRAK
Penelitian ini bertujuan untuk melihat pengaruh kepemimpinan transformasional dan motivasi kerja terhadap kinerja pegawai. Metode yang digunakan dalam penelitian ini adalah metode kuntitatif verifikatif. Instumen yang digunakan adalah kuesioner yang berjumlah 15 pernyataan yang diberikan kepada 60 orang karyawan TAF. Pengambilan sampel dilakukan dengan teknik aksidental (convenient sampling). Data penelitian dianalisis dengan menggunakan Smart PLS versi 3.0. Hasil penelitian menunjukkan bahwa kepemimpinan transformasional berpengaruh signifikan terhadap kinerja pegawai $(p<0,05)$, motivasi kerja tidak berpengaruh signifikan terhadap kinerja pegawai $(p>0,05)$, dan kepemimpinan transformasional yang dimediasi oleh motivasi tidak berpengaruh signifikan terhadap kinerja pegawai $(\mathrm{p}>0,05)$. Penelitian lanjutan diharapkan dapat membuat suatu model peningkatan kepemimpinan transformasional yang dapat meningkatkan motivasi dan kinerja pegawai.
\end{abstract}

\section{Kata Kunci: Kepemimpinan Transformasional, Kinerja Pegawai, Motivasi}




\section{PENDAHULUAN}

Munculnya

industrial

revolution (IR) 4.0 dan society 5.0 mengubah cara hidup dan kerja kita. Perubahan teknologi ini juga mengubah standarisasi pasar, sehingga semua perusahaan perlu menyesuaikan dengan standar yang baru (Schwab, 2016). Guna menyikapi hal tersebut setiap perusahaan perlu meningkatkan level mereka supaya mereka tetap dapat kompetitif. Vosloban (2012) mengungkapkan bahwa salah satu aspek paling penting dalam meningkatkan level perusahaan adalah sumber daya manusia. Sumber daya manusia merupakan kunci pokok untuk menentukan keberhasilan pelaksanaan kegiatan perusahaan secara berkelanjutan. Sumber daya manusia merupakan investasi yang paling penting yang dapat dilakukan oleh perusahaan yang bermuara pada kinerja pegawai yang baik.

Kinerja pegawai atau dikenal juga prestasi kerja dapat didefinisikan sebagai perbandingan antara hasil kerja yang dapat dilihat secara nyata dengan standar kerja yang telah ditetapkan oleh suatu organisasi (Gonnah \& Ogollah, 2016; Omolo, 2015). Mencapai level kinerja yang tinggi memiliki banyak tantangan, mengingat pengembangan perusahaan yang perlu terus dilakukan secara berkelanjutan. Hal ini tidak hanya berkaitan dengan kualitas layanan dan produk, akan tetapi juga tenaga kerja yang berprestasi. Agar aktivitas perusahaan berjalan dengan baik, perusahaan harus memiliki karyawan yang berkualitas dan berpotensi tinggi. Kualitas dan potensi dari setiap sumber daya manusia yang ada dalam organisasi perusahaan harus dapat dimanfaatkan dengan sebaik-baiknya, sehingga mampu mengelola perusahaan seoptimal mungkin agar kinerja karyawan meningkat.

Peningkatan kerja karyawan akan membawa kemajuan bagi perusahaan untuk bertahan dalam suatu persaingan di lingkungan bisnis yang tidak stabil. Pencapaian tujuan perusahaan akan tergambar dalam kinerja karyawan yang ada dalam suatu perusahaan. Kinerja perusahaan tergantung dari kinerja individu atau sebaliknya di mana kinerja individu akan memberikan kontribusi terhadap kinerja organisasi (Prajogo, 2007). Artinya bahwa perilaku karyawan baik secara individu maupun kelompok akan memberikan kekuatan atas kinerja perusahaan.

Salah satu perusahaan atau industri yang memiliki peran penting dalam pola pergerakan arus modal adalah perusahaan pembiayaan (Martani \& Munaiseche, 2010). Awalnya perusahaan pembiayaan hanya bergerak pada sektor penyewaan alat berat bagi perusahaan yang tidak mampu membelinya, akan tetapi saat ini perusahaan pembiayaan mulai pindah ke berbagai pembiayaan segmen baru, termasuk memperluas sewa menyewa, anak piutang, pembiayaan konsumen, dan penerbitan kartu kredit (Hope \& Vyas, 2017). Perusahaan pembiayaan membantu konsumen dalam memberikan pinjaman sementara yang terlibat dalam kegiatan kredit komersial berdasarkan nilai aset yang dijaminkan oleh peminjam sebagai jaminan.

PT Toyota Astra Finance (TAF) merupakan perusahaan pembiayaan 
yang bergerak dalam pembiayaan multiguna untuk kepemilikan kendaraan roda empat, fasilitas pembiayaan investasi, dan modal kerja. TAF sebagai salah satu badan usaha pembiayaan dituntut untuk bekerja melayani dan memberikan informasi seefisien mungkin agar pekerjaan yang dibebankan bisa dikerjakan sesuai dengan yang diharapkan sehingga kebutuhan pengunjung dapat terpenuhi. Studi pendahuluan terhadap beberapa aspek penilaian kinerja pegawai TAF pada salah satu cabang memperlihatkan bahwa pencapaian kinerja berada pada kategori cukup baik (Tabel 1). Kategori baik hanya berada pada aspek pengetahuan terhadap pekerjaan, kehadiran, dan kecepatan pelayanan. Tentunya peningkatan terhadap kinerja pegawai TAF merupakan hal yang perlu ditingkatkan secara berkelanjutan (sustainability development).

Tabel 1. Penilaian kinerja pada salah satu cabang TAF

\begin{tabular}{|c|c|c|}
\hline Aspek Penilaian & Skor & Kategori \\
\hline Pengetahuan terhadap pekerjaan & 79 & Baik \\
\hline Komunikasi terhadap rekan kerja dan atasan & 61 & Cukup Baik \\
\hline Integritas & 69 & Cukup Baik \\
\hline Kedisiplinan petugas pelayanan & 65 & Cukup Baik \\
\hline Kehadiran & 70 & Baik \\
\hline Kerja sama & 65 & Cukup Baik \\
\hline Tanggung jawab terhadap pekerjaan & 69 & Cukup Baik \\
\hline Inisiatif & 62 & Cukup Baik \\
\hline Prosedur pelayanan & 67 & Cukup Baik \\
\hline Kemampuan petugas pelayanan & 68 & Cukup Baik \\
\hline Kecepatan pelayanan & 75 & Baik \\
\hline Rata-rata & 68,18 & Cukup Baik \\
\hline
\end{tabular}

Sumber: Data primer kinerja pegawai salah satu cabang TAF di Bandung

Beberapa penelitian telah mendeskripsikan bahwa faktor-faktor yang mempengaruhi kinerja pegawai adalah tekanan pekerjaan (job stress), motivasi (motivation), kepemimpinan transformasional (transfromational leadership), dan komunikasi (communication) (Jha \& Malviya, 2017; Muda, Rafiki, \& Harahap, 2014). Kepemimpinan transformasional dan motivasi merupakan hal yang menarik untuk diteliti karena berkaitan faktor ekstrinsik dan intrinsik. Kepemimpinan transformasional merupakan suatu model kepemimpinan untuk menciptakan sebuah visi perubahan dan pada akhirnya dapat memotivasi pegawai untuk mencapai tujuan yang telah ditetapkan (Gonnah \& Ogollah, 2016), sedangkan motivasi merupakan suatu kekuatan yang mampu membuat seseorang untuk meningkatkan semangat kerja dan berdampak pada peningkatan produktivitas kerja (Andriani, Kesumawati, \& Kristiawan, 2018). Hasil penelitian sebelumnya yang dilakukan oleh Muda et al., (2014) menunjukkan bahwa kepemimpinan transformasional memiliki hubungan yang positif dengan motivasi pegawai. Penelitian lain yang dilakukan oleh Nugroho \& Aima (2018) memperlihatkan bahwa kepemimpinan transformasional dan kompensasi memiliki pengaruh yang signifikan terhadap kinerja pegawai. Shahzadi et al., (2014) menemukan 
bahwa motivasi kerja memiliki hubungan positif dengan kinerja pegawai.

\section{Kepemimpinan}

transformasioanal dan motivasi memiliki posisi strategis pada TAF dalam memberikan pelayanan yang terbaik dalam hal memberikan pinjaman kepada pelanggan. TAF memberikan fasilitas dalam pembiayaan kendaraan, mulai dari perhitungan angsuran mobil, kemudahan dalam pengajuan kredit mobil, pembiayaan kompetitif, hingga pembayaran angsuran yang fleksibel sesuai kebutuhan. Fokus kerja dari TAF adalah kepuasan pelanggan, di mana setiap kerja dan pelayanan yang diberikan selalu berfokus kepada pelanggan (customer oriented). Penelitian ini bertujuan untuk melihat pengaruh kepemimpinan transformasional dan motivasi terhadap kinerja pegawai TAF.

\section{METODE PENELITIAN}

Metode penelitian yang digunakan dalam penelitian ini adalah metode verifikatif untuk melihat pengaruh kepemimpinan transformasional dan motivasi terhadap kinerja pegawai. Instrumen yang digunakan dalam penelitian ini adalah kuesioner dengan menggunakan skala Likert. Kuesioner berisi 15 pernyataan positif dan negatif yang diberikan kepada 60 orang karyawan TAF yang dipilih berdasarkan teknik pengambilan sampel aksidental (convenient sampling). Teknik sampling aksidental merupakan pengambilan sampel berdasarkan ketersediaan sampel dan dipandang sampel tersebut cocok sebagai sumber data
(Ali et al., 2016). Proses pengumpulan data dilakukan selama periode dua bulan yang dimulai dengan observasi, wawancara dan pemberian kuesioner. Data dari setiap variabel yang diperoleh dianalisis dengan menggunakan perangkat lunak Smart PLS versi 3.0.

Variabel bebas pertama dalam penelitian ini adalah kepemimpinan transformaisonal (X1) yang terdiri dari empat indikator yaitu pengaruh ideal (charisma), motivasi inspirasi (inspirational motivation), stimulasi intelektual (intellectual stimulation), dan pertimbangan individu (individualized consideration) (Bass, et al., 2003). Variabel bebas kedua dalam penelitian ini adalah (X2) motivasi yang terdiri dari tiga indikator, meliputi kebutuhan berprestasi (need for acchievment), kebutuhan akan afiliasi (need for affiliation), dan kebutuhan akan kekuasaan (need for power) (McClellan dalam Pardee, 1990). Variabel terikat (Y) merupakan kinerja pegawai, yang terdiri dari kuantitas bekerja (quantity of work), kualitas bekerja (quality of work), inisiatif (initiative), dapat dipercaya (defendability) dan kerjasama (cooperation) (Bernardin \& Russel, 1993).

Penelitian sebelumnya secara terpisah menemukan bahwa transformasi kerja dan motivasi memiliki pengaruh signifikan kinerja pegawai (Gonnah \& Ogollah, 2016; Muda et al., 2014). Nugroho \& Aima (2018) berpendapat bahwa kepemimpinan transformaional memiliki pengaruh tidak langsung terhadap kinerja pegawai. Oleh karena itu, analisis tidak hanya dilakukan pada besarnya pengaruh 
langsung (direct effect) X1 terhadap $\mathrm{Y}$ atau $\mathrm{X} 2$ terhadap $\mathrm{Y}$, akan tetapi juga pengaruh $\mathrm{X} 1$ yang dimediasi $\mathrm{X} 2$ terhadap Y (indirect effect). Kerangka berpikir model analisis ditunjukkan pada Gambar 1.

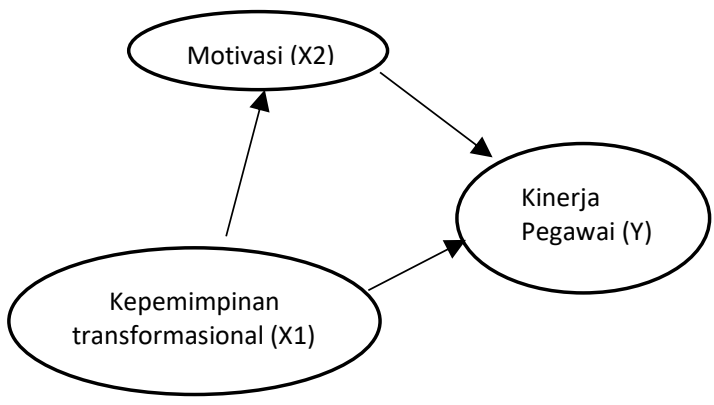

Gambar 1. Kerangka Kerja Penelitian

\section{HASIL PENELITIAN DAN PEMBAHASAN}

1. Validitas dan Reliabilitas Pengujian indikator instrumen dilakukan dengan menetapkan validitas dan reliabilitas indikator yang mengukur setiap laten variabel. Persyaratan minimum agar dapat dianggap valid apabila $r=0,300$. Sehingga apabila korelasi antar item dengan skor total kurang dari 0,300 maka item dalam instrumen tersebut dinyatakan tidak valid (Sugiyono, 2011). Sedangkan pengujian reliabilitas dilakukan dengan teknik belah dua (split half). Suatu instrumen variabel dikatakan reliabel apabila memperoleh nilai koefisien reliable bernilai positif lebih besar dari 0,700 atau $70 \%$ dan semakin tinggi tingkat reliabilitasnya semakin konsisten instrumen tersebut. Hasil pengujian validitas dan reliabilitas instrumen ditunjukkan pada Tabel 2.

Tabel 2. Hasil analisis validitas dan reliabilitas

\begin{tabular}{|c|c|c|c|c|c|c|}
\hline \multirow[t]{2}{*}{ Item } & \multicolumn{2}{|c|}{$\begin{array}{l}\text { Kepemimpinan } \\
\text { Transformasional }\end{array}$} & \multicolumn{2}{|c|}{ Motivasi } & \multicolumn{2}{|c|}{ Kinerja Pegawai } \\
\hline & Validitas & Reliabilitas & Validitas & Reliabilitas & Validitas & Reliabilitas \\
\hline 1 & 0,729 & & 0,371 & & 0,402 & \\
\hline 2 & 0,516 & & 0,577 & & 0,446 & \\
\hline 3 & 0,367 & & 0,467 & & 0,403 & \\
\hline 4 & 0,412 & & 0,357 & & 0,372 & \\
\hline 5 & 0,527 & & 0,326 & & 0,464 & \\
\hline 6 & 0,435 & & 0,417 & & 0,344 & \\
\hline 7 & 0,526 & & 0,417 & & 0,488 & \\
\hline 8 & 0,637 & 0,856 & 0,401 & 0,806 & 0,611 & 0,834 \\
\hline 9 & 0,468 & & 0,407 & & 0,495 & \\
\hline 10 & 0,445 & & 0,463 & & 0,468 & \\
\hline 11 & 0,384 & & 0,360 & & 0,442 & \\
\hline 12 & 0,509 & & 0,336 & & 0,423 & \\
\hline 13 & 0,462 & & 0,478 & & 0,488 & \\
\hline 14 & 0,623 & & 0,377 & & 0,588 & \\
\hline 15 & 0,377 & & 0,493 & & 0,456 & \\
\hline
\end{tabular}

Sumber: Hasil analisis data menggunakan SPSS versi 20.

Berdasarkan hasil pengujian validitas dan reliabilitas instrumen menunjukkan bahwa validitas instrumen kepemimpinan transformasional, motivasi dan kinerja pegawai lebih besar dari nilai kritis $(r=0,300)$. Begitupun dengan nilai reliabilitas yang dihitung berdasarkan nilai Cronbach Alpha yang berada pada kategori tinggi. Sehingga dapat disimpulkan bahwa instrumen 
yang digunakan memenuhi nilai validitas dan reliabilitas yang ditetapkan.

2. Analisis Jalur Path

Setelah validitas dan reliabilitas instrumen dianalisis, langkah selanjutnya adalah melakukan analisis jalur path berdasarkan model kerangka kerja yang telah dibuat pada Gambar 1 . Kerangka kerja pada Gambar 1 menunjukkan hubungan antara setiap variabel laten berdasarkan teori substantif. Pengujian jalur path dihitung berdasarkan nilai koefesien path yang dibantu oleh software Smart PLS versi 3.0. Nilai koefisien path menggambarkan kekuatan hubungan antara konstrak atau variabel yang ditunjukkan pada Gambar 2.

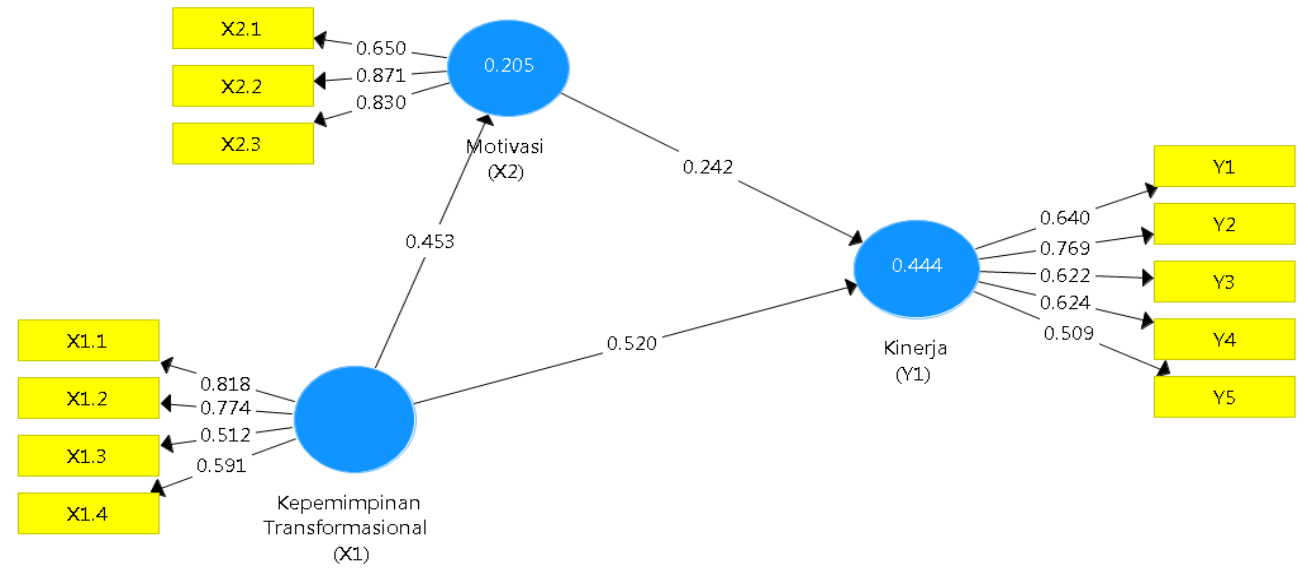

Sumber: Hasil analisis data menggunakan SMART PLS

Gambar 2. Model analisis jalur path

Gambar 2 memperlihatkan nilai

$\mathrm{R}$ squared pada structural equation model (SEM) dari setiap laten variabel yang dianalisis. Terlihat bahwa pengaruh kepemimpinan transfromasional (X1) terhadap kinerja pegawai $(\mathrm{Y})$ adalah sebesar $0,520(52,0 \%)$. pengaruh motivasi kerja (X2) terhadap kinerja pegawai (Y) adalah sebesar 0,245 (24,5\%), dan pengaruh kepemimpinan transformasional (X1) terhadap motivasi kerja (X2) adalah sebesar $0,453(45,3 \%)$. Hasil analisis ini menunjukkan bahwa setiap laten variabel yang dianalisis memiliki pengaruh dengan laten variabel lainnya. Hasil analisis $\mathrm{R}$ squared tersebut dibandingkan dengan pengaruh total langsung dan tidak langsung. Muller \& Judd (2014) menjelaskan bahwa pengaruh langsung adalah pengaruh yang diberikan secara langsung oleh variabel bebas kepada variabel terikat, sedangkan pengaruh tidak langsung adalah pengaruh yang diberikan oleh variabel bebas kepada variabel terikat melalui variabel lainnya. Variabel lain tersebut dapat berupa variabel bebas lain atau variabel intervening. Dalam kasus ini pengaruh langsung diberikan oleh X1 terhadap $\mathrm{Y}$ dan $\mathrm{X} 2$ terhadap $\mathrm{Y}$, sedangkan pengaruh tidak langsung adalah X1 terhadap Y melalui X2. Analisis pengaruh langsung dan pengaruh tidak langsung diperlihatkan pada Tabel 3 . 
Tabel 3. Pengaruh langsung dan tidak langsung variabel bebas terhadap variabel terikat

\begin{tabular}{lccccc}
\hline \multirow{2}{*}{ Variabel } & \multirow{2}{*}{$\begin{array}{c}\text { Pengaruh } \\
\text { Langsung }\end{array}$} & \multicolumn{2}{c}{$\begin{array}{c}\text { Pengaruh Tidak } \\
\text { Langsung }\end{array}$} & \multirow{2}{*}{$\begin{array}{c}\text { Pengaruh } \\
\text { Total }\end{array}$} \\
\cline { 3 - 4 } & & $\mathbf{X}_{\mathbf{1}}$ & $\mathbf{X}_{\mathbf{2}}$ & \\
\hline Kepemimpinan & 0,520 & & - & 0,110 & 0,630 \\
$\begin{array}{l}\text { Transformasional } \\
\text { Motivasi }\end{array}$ & 0,242 & 0,110 & - & 0,352 \\
& Pengaruh Total & & & \\
\hline
\end{tabular}

Berdasarkan penyajian Tabel 3 ditemukan bahwa pengaruh total dari kepemimpinan transformasional adalah sebesar 0,630 dan pengaruh total dari motivasi adalah 0,352 . Terlihat bahwa pengaruh tidak langsung memiliki koefesien yang sangat kecil, sebesar 0,110. Pengaruh tidak langsung ini merupakan pengaruh dari X1 melalui variabel X2 terhadap variabel $\mathrm{Y}$. Untuk melihat signifikansi perbedaan pada setiap variabel tersebut perlu dilakukan analisis lanjutan. Analisis lanjutan yaitu uji signifikansi dengan membandingkan nilai $\mathrm{t}$ hitung dan $\mathrm{t}$ tabel. Hasil uji signifikansi dapat dilihat pada Tabel 4.

Tabel 4. Uji signifikansi pengaruh langsung dan tidak langsung

\begin{tabular}{|c|c|c|c|c|c|}
\hline Variabel & $\begin{array}{c}\text { Jenis } \\
\text { Pengaruh }\end{array}$ & Mean & $\begin{array}{r}\text { Standar } \\
\text { deviasi }\end{array}$ & T Statistik & $\mathrm{p}$ \\
\hline $\begin{array}{l}\mathrm{X} 1 \rightarrow \mathrm{Y} \\
\mathrm{X} 2 \rightarrow \mathrm{Y}\end{array}$ & Langsung & 0,534 & $\begin{array}{l}0,130 \\
0245\end{array}$ & 4,009 & 0,000 \\
\hline $\mathrm{X} 1 \rightarrow \mathrm{X} 2 \rightarrow \mathrm{Y}$ & $\begin{array}{l}\text { Tidak } \\
\text { langsung }\end{array}$ & 0,116 & 0,068 & 1,615 & 0,107 \\
\hline
\end{tabular}

Tabel 4 memperlihatkan bahwa pengaruh langsung dari $\mathrm{X} 1$ terhadap $\mathrm{Y}$ memiliki pengaruh yang signifikan $(\mathrm{p}<0,05)$. Artinya bahwa kepemimpinan transformasional berpengaruh secara signifikan terhadap kinerja pegawai. Penelitian ini sejalan dengan penelitian sebelumnya yang menemukan bahwa kepemimpinan transformasional berpengaruh signifikan terhadap kinerja pegawai (Andriani et al., 2018; Nugroho \& Aima, 2018; Tabassi, Ramli, \& Dashti, 2014). Kepemimpinan transformasional berkaitan dengan jiwa personal yang kuat dari pemimpin dalam menciptakan visi suatu organisasi yang dibangun melalui hubungan pemimpin dan pegawai (Keegan \&
Den Hartog, 2004). Hubungan yang terbangun ini menciptakan hubungan yang lebih dari sekedar imbalan, akan tetapi menjadi suatu kepatuhan (compliance).

Sementara itu, pengaruh langsung dari X2 terhadap Y tidak memiliki pengaruh yang signifikan ( $p>0,05)$. Hal ini menunjukkan bahwa motivasi kerja tidak memiliki pengaruh signifikan terhadap kinerja pegawai. Penelitian ini bertentangan dengan penelitian sebelumnya yang menyatakan bahwa motivasi kerja memiliki pengaruh yang signifikan terhadap kinerja pegawai dan kepuasan kerja perusahaan IT di Pakistan (Ali et al., 2016). Akan tetapi, sesuai dengan penelitian yang dilakukan oleh Nugroho \& Aima 
(2018) yang menyatakan bahwa motivasi tidak memiliki pengaruh yang signifikan terhadap kinerja pegawai. Shahzadi et al. (2014) mengungkapkan bahwa motivasi kerja berorientasi pada kebebasan dan otonomi yang diatur secara personal. Hal ini berkaitan dengan kemampuan dalam memanfaatkan peluang pengembangan yang lebih tepat.

Tabel 4 juga memperlihatkan pengaruh tidak langsung yang diberikan oleh kepemimpinan transformasional melalui motivasi terhadap kinerja pegawai. Pengaruh yang diberikan oleh pengaruh tidak langsung ini memberikan pengaruh yang tidak signifikan ( $p>0,107)$. Dalam hal ini menunjukkan bahwa kepemimpinan transformasional yang dimediasi oleh motivasi memberikan pengaruh positif namun tidak signifikan. Artinya kepemimpinan transformasional yang dimediasi oleh motivasi tidak memberikan pengaruh nyata terhadap kinerja pegawai TAF. Penelitian ini bertolak belakang dengan penelitian sebelumnya yang dilakukan oleh Priyanto (2016), yang menemukan bahwa kepemimpinan transformasional yang dimediasi oleh motivasi memberikan pengaruh signifikan terhadap kinerja pegawai. Motivasi merupakan dorongan diri yang timbul dari dalam diri seseorang untuk mencapai tujuan tertentu. Motivasi menjadi elemen penting bagi suatu organisasi dalam meningkatkan pelayanannya (Osabiya, 2015)

Hasil penelitian ini menunjukkan bahwa kinerja pegawai TAF belum optimal disebabkan karena motivasi kerja yang belum optimal. Kinerja pegawai yang diperoleh secara signifikan lebih dipengaruhi oleh kepemimpinan transformasional dibandingkan dengan motivasi. Secara tidak langsung pemimpin juga belum mampu meningkatkan motivasi kerja pegawainya. Motivasi dapat dibangun dalam diri seseorang (intrinsik) atau dapat muncul sebagai akibat dari pengaruh dari luar (ekstrinsik) (Putra \& Frianto, 2018). Shahzadi et al. (2014) mengungkapkan lebih jauh bahwa motivasi ini dapat timbul melalui faktor penghargaan intrinsik seperti pengakuan dan promosi, serta peningkatan kinerja melalui kegiatan pelatihan.

\section{PENUTUP}

Berdasarkan hasil penelitian dan diskusi, dapat disimpulkan bahwa kinerja pegawai TAF lebih di pengaruhi oleh kepemimpinan transformasional dibandingkan dengan motivasi kerja. Peningkatan kinerja pegawai dapat dikembangkan dengan meningkatkan motivasi kerja melalui pemberian penghargaan atau pelatihan kerja yang sifatnya berkelanjutan. Hal ini terlihat dari dimensi motivasi kerja yang paling rendah adalah kebutuhan untuk berprestasi. Kebutuhan pegawai untuk berprestasi masih rendah dalam hal mencapai kinerja dalam standar yang tinggi. Motivasi kerja pegawai lebih didominasi oleh kebutuhan akan kekuatan dan afiliasi. Penelitian lanjutan diharapkan mampu mengembangkan suatu model peningkatan kepemimpinan transformasional untuk mengembangkan motivasi dan kinerja pegawai TAF.

\section{DAFTAR PUSTAKA}

Ali, A., Bin, L. Z., Piang, H. J., \& Ali, 
Z. 2016. The Impact of Motivation on the Employee Performance and Job Satisfaction in IT Park (Software House) Sector of Peshawar, Pakistan. International Journal of Academic Research in Business and Social Sciences, 6(9), 297310.

https://doi.org/10.6007/ijarbss/ v6-i9/2311

Andriani, S., Kesumawati, N., \& Kristiawan, M. 2018. The influence of the transformational leadership and work motivation on teachers performance. International Journal of Scientific and Technology Research, 7(7), 1929.

Bass, B. M., Avolio, B. J., Jung, D. I., \& Berson, Y. 2003. Predicting unit performance by assessing transformational and transactional leadership. Journal of Applied Psychology. https://doi.org/10.1037/00219010.88.2.207

Bernardin, H. J., \& Russel, J. E.1993. Human Resourses management. New York: Mc Graw Hill Inc.

Gonnah, B. J., \& Ogollah, K. 2016. Effect of Transformational Leadership on Performance of Commercial Banks in Kenya: Case of Family Bank Limited. International Academic Journal of Innovation, Leadership and Entrepreneurship, 2(1), 1-25. Retrieved from http://www.iajournals.org/articl es/iajile_v2_i1_1_25.pdf

Hope, O. K., \& Vyas, D. 2017.
Private company finance and financial reporting. Accounting and Business Research. https://doi.org/10.1080/000147 88.2017.1303963

Jha, S., \& Malviya, V. 2017. Impact of transformational leadership on employee engagement. Pranjana:The Journal of Management Awareness, 20(2), 15.

https://doi.org/10.5958/09740945.2017.00011.5

Keegan, A. E., \& Den Hartog, D. N. 2004. Transformational leadership in a project-based environment: A comparative study of the leadership styles of project managers and line managers. International Journal of Project Management, 22(8), 609-617. https://doi.org/10.1016/j.ijprom an.2004.05.005

Martani, D., \& Munaiseche, R. R. 2010. Factors affecting profitability of multi-finance company in Indonesia, 9(5), 53-63.

Muda, I., Rafiki, A., \& Harahap, M. R. 2014. Factors Influencing Employees ' Performance: A Study on the Islamic Banks in Indonesia. International Journal of Business and Social Sience, 5(2), 73-80.

Muller, D., \& Judd, C. M. 2014. Direct and Indirect Effects. In Wiley StatsRef: Statistics Reference Online. https://doi.org/10.1002/978111 8445112.stat06589

Nugroho, G. S., \& Havidz Aima, M. 2018. The Influences Of Transformational Leadership And Compensation To 
Employee Performance On Their Motivation And The Implementation At $\mathrm{X}$ Institution. International Journal of Scientific and Research Publications (IJSRP), $8(12)$. https://doi.org/10.29322/ijsrp.8 .12.2018.p8447

Omolo, P. A. 2015. Effect of motivation on employee performance of commercial banks in Kenya: A case study of Kenya Commercial Bank in Migori County. International Journal of Human Resource Studies, 5(2), 87. https://doi.org/10.5296/ijhrs.v5 i2.7504

Osabiya, B. J. 2015. The effect of employees motivation on organizational performance. Journal of Public Administration and Policy Research.

https://doi.org/10.5897/jpapr20 14.0300

Pardee, R. 1990. Motivation Theories of Maslow, Herzberg, McGregor \& McClelland. A Literature Review of Selected Theories Dealing with Job Satisfaction and Motivation. Synopsis of Selected Motivational Theories.

Prajogo, D. I. 2007. The relationship between competitive strategies and product quality. Industrial Management and Data Systems, 107(1), 69-83. https://doi.org/10.1108/026355 70710719061
Priyanto, W. B. 2016. Pengaruh Gaya Kepemimpinan Kinerja Karyawan Dengan Motivasi Sebagai, 07(02), 105-114.

Putra, A. K., \& Frianto, A. 2018. Pengaruh Motivasi Intrinsik dan Motivasi Ekstrinsik terhadap Kepuasan Kerja. BISMA (Bisnis Dan Manajemen).

https://doi.org/10.26740/bisma. v6n1.p59-66

Schwab, K. 2016. The Fourth Industrial Revolution: what it means and how to respond. World Economic Forum.

Shahzadi, I., Javed, A., Pirzada, S. S. Nasreen, S., \& Khanam, F. 2014. Impact of Employee Motivation on Employee Performance. European Journal of Business and ManagementOnline), 6(23), 2222-2839.

Sugiyono. 2011. Metode Penelitian Kuantitatif, Kualitatif dan $R \& D$. Bandung: Afabeta

Tabassi, A. A., Ramli, M., \& Dashti, K. F. 2014. Transformational Leadership and Team Effectiveness in the Construction Industry. Strategic Leadership Review, 3(4).

Vosloban, R. I. 2012. The Influence of the Employee's Performance on the Company's Growth - A Managerial Perspective. Procedia Economics and Finance, 3(12), 660-665. https://doi.org/10.1016/s22125671(12)00211-0. 